\title{
From Push To Pull: Emerging Models For Mobilizing Resources
}

John Hagel III, Deloitte LLP Center for Edge Innovation

John Seely Brown, Deloitte LLP Center for Edge Innovation

\section{INTRODUCTION}

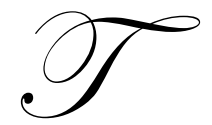

he signs are around us. We are on the cusp of a shift to a new common sense model that will reshape many facets of our life, including how we identify ourselves, participate with others, connect with others, mobilize resources and learn. This paper will focus on only one facet of this new common sense model - emerging approaches for mobilizing resources.

Over the past century, we have been perfecting highly efficient approaches to mobilizing resources. These approaches may vary in their details, but they share a common foundation. They are all designed to "push" resources in advance to areas of highest anticipated need. In education, we design standard curricula to expose students to codified information in a pre-determined sequence of experiences. In business, we build highly automated plants or service platforms supported by standardized processes seeking to deliver resources to the right place at pre-determined times. In technology, we write massive enterprise applications specifying activities that must be performed and resources that must be deployed to meet anticipated demand.

In the past decade, we have seen early signs of a new model for mobilizing resources. Rather than "push", this new approach focuses on "pull" - creating platforms that help people to mobilize appropriate resources when the need arises. In lean manufacturing, early elements of a pull model began to emerge from Toyota in the early 1950's. As we will discuss below, however, lean manufacturing represents a hybrid between push and pull models it still contains significant elements of push models.

More fully developed pull models would take several more decades to emerge in arenas as diverse as media and advertising, global process networks and education. These are not just isolated examples - powerful forces are at work shaping the need for an alternative approach to mobilizing resources. These forces ensure that this new model will spread to all arenas of human activity.

Pull models are emerging as a response to growing uncertainty. Instead of dealing with uncertainty through tighter control, pull models do the opposite. They seek to expand the opportunity for creativity by local participants dealing with immediate needs. To exploit the opportunities created by uncertainty, pull models help people to come together and innovate in response to unanticipated events, drawing upon a growing array of highly specialized and distributed resources. Rather than seeking to constrain the resources available to people, pull models strive to continually expand the choices available while at the same time helping people to find the resources that are most relevant to them. Rather than seeking to dictate the actions that people must take, pull models seek to provide people on the periphery with the tools and resources (including connections to other people) required to take initiative and creatively address opportunities as they arise. Push models treat people as passive consumers (even when they are producers like workers on an assembly line) whose needs can be anticipated and shaped by centralized decisionmakers. Pull models treat people as networked creators (even when they are customers purchasing goods and services) who are uniquely positioned to transform uncertainty from a problem into an opportunity. Pull models are ultimately designed to accelerate capability building by participants, helping them to learn as well as innovate, by pursuing trajectories of learning that are tailored to their specific needs.

By mastering the techniques required to make this new model work, companies will be well-positioned to create substantial economic value. Those who adhere rigidly to the old model will likely destroy significant economic value. 


\section{Early Signs of the New Model}

As William Gibson reminds us, "the future is already here, it is just unevenly distributed." 'We are beginning to see early signs of new models for resource mobilization in diverse arenas, from media to global process networks to education. Even within these arenas, however, the new models are still operating in very early form at the peripheries of more mature push models - often, as in education, they are emerging under the radar, in areas that we would not first think to look.

\section{Media}

Over the past decade, we have witnessed a transformation of the media landscape. On the one hand, mass media is becoming more concentrated in terms of ownership as audiences and revenue sources slowly decline. On the other hand, we are witnessing a blossoming of niche content, aided by four converging developments: the development of low cost and easily accessible content creation tools, the spread of the Internet as an infrastructure for content distribution, the growth of new forms of access devices and the emergence of new types of distribution businesses facilitating the transition to pull models of content distribution.

Anything that can be digitized can be accessed and distributed on the Internet. As bandwidth has increased and compression algorithms have improved, we have seen a migration from text-based content to music and now to video in terms of using the Internet as a platform for access and distribution. At the same time more powerful, compact and mobile access devices like MP3 players and digital video recorders like Tivo are making it easier to find and connect with relevant content.

Rather than waiting for media companies to deliver relevant content at appropriate times, customers are increasingly reaching out to pull content to them when they want. They are aided in this task by new distribution businesses that are breaking down the shelf space constraints of traditional distribution channels, radically expanding the range of content that is available and providing robust tools to help customers find the content that is most relevant to them. Sometimes these new businesses look like more conventional retailers in the sense of providing a single point of access to broad assortments of media (e.g., Amazon or Netflix). Sometimes they provide new ways of sampling media before buying (e.g., Rhapsody). But others are quite different, ranging from eBay where the closest analogue is the local flea market to peer to peer networks that lack any central hub at all and enable owners of content to pull from each other directly.

But the changes to the media business are not restricted to distribution - pull approaches are also emerging in media production, leading to a further proliferation in media choices. At the most basic level, younger generations of customers are increasingly customizing media to better suit their individual needs. For example, rather than relying on music companies to pre-determine the mix of songs on a $\mathrm{CD}$, an increasing number of music listeners are downloading individual tracks and assembling their own tailored sequence of songs. "Podcasters" are also emerging to share customized selections of music from many different artists with friends and broader audiences. A vibrant remix culture has also emerged, assisted by widely affordable digital audio editing tools, in which DJ's in night clubs and other music fans recombine and, in some cases, add audio tracks or channels from a recording to produce a modified audio recording.

Perhaps the area that has received the most attention recently is the rise of blogging. Blogging tools provide everyone with the capability of quickly "publishing" their perspectives and creative content like music, photos and even video and making it broadly available to others. These blogging tools are further augmented by increasingly inexpensive but ever more powerful digital content creation tools, ranging from digital still cameras and videocameras (often embedded in mobile telephones for even more rapid transmission to the Internet) to digital music creation and remixing platforms. Media production is no longer the exclusive province of professionals talented pro-ams are harnessing these new tools to make their voices heard and creative talents seen.

Blogs also enable everyone to become "editors", pulling together the content of others, remixing it in creative ways and adding commentary. Suddenly, those who never published before like Joi Ito, editor of the Joi Ito 
Web blog, and Ana Marie Cox, editor of the Wonkette blog, are emerging quickly on the Internet and attracting large audiences. Often, those who are at the cutting edge of inquiry where journals either don't exist or are too slow in getting ideas out find blogs a powerful way to engage in discussions to test and refine their ideas. The informal, highly personal style of many blogs also provides interesting new ways for readers to get a better sense of the person behind the blog, allowing them to "read" the content offered on the blog in a much richer context. All of this variety and richness available in the blogging world can be accessed and further tailored by the audience through versatile aggregation tools like Technorati and Bloglines.

\section{Global Process Networks}

Ah, but the skeptic will reply, media is different because it can be digitized and distributed directly over electronic networks like the Internet. Besides, media has always been a bit of a "strange" business, nothing like the work that most enterprises do. What about the world of atoms - physical products that can't be produced or distributed on electronic networks?

Pull models are also emerging here. Look at the three core operating processes of the firm - supply chain management (including manufacturing and logistics), product innovation and commercialization and customer relationship management. Innovative pull models for organizing activities in these processes across large numbers of enterprises are beginning to emerge in industries as diverse as apparel, motorcycles and computers. We describe these pull models as global process networks. Many of the most innovative pioneers in developing these pull models are located in China, but some companies in the U.S. are beginning to master these pull techniques as well.

Perhaps the most sophisticated practitioner of these pull models on a global scale is Hong Kong-based Li \& Fung, which helps apparel designers to configure and operate highly customized supply chains to produce and distribute apparel to retailers around the world.Li \& Fung works with 10,000 business partners in 40 countries to ensure that the right specialized partners are mobilized for a high end wool sweater but then calling on a completely different set of partners to produce and distribute synthetic fiber men's slacks. In sharp contrast to traditional supply chain managers which have focused on limiting the number of supply chain partners and creating tightly integrated operations, the orchestrators of these global process networks are rapidly expanding the range of participants to provide an even broader range of specialized capability that can be flexibly "pulled" by individual customers to serve their specific needs.

The pull platform created by Li \& Fung, bringing together thousands of highly specialized business partners from around the world, only works because Li \& Fung has invested considerable time and effort over decades to build long-term, trust-based relationships with each of its partners. These relationships endure and thrive because Li \& Fung has found ways to help its partners deepen their capability over time and to strike the right balance between dependence and independence within its partner network. Organizers of successful process networks pay careful attention to building relationships that enable all parties to accelerate their capability building.

Li \& Fung provides an example of a very different pull model emerging in supply chain management. Taiwanese ODM's like Quanta and Compal offer equally compelling examples of the application of pull models in distributed product innovation and commercialization processes. These ODM's creatively pull together highly specialized component and sub-system suppliers to generate ideas for delivering higher performance at lower cost in a broad range of digital devices, including notebook computers, digital still cameras and mobile telephones. In this case, the success of these "pull" models is helping to put even more inexpensive devices in the hands of customers, helping to spur the proliferation of new digital media and increasing the value of pull-oriented media creation and distribution mechanisms discussed earlier. More informal open innovation techniques to pull ideas from broadly distributed parties are being deployed by such diverse institutions as NASA, Nokia and Merck.

Cisco illustrates how the pull model can be applied to complex and distributed customer relationship management activities. In this case, Cisco helps its customers by pulling together appropriate capabilities from thousands of specialized channel partners to address individual customer needs across the entire lifecycle from needs definition to deployment to use. 


\section{Education, Training and Learning}

Mention learning and the instinct of most people is to look at traditional educational institutions, particularly primary and secondary education and colleges. But some of the most interesting innovations in education are going on outside these traditional institutions. Many of these innovations involve a transition to pull models of learning.

Take the example of University of Phoenix, one of the fastest growing educational institutions in the United States. Its name makes it sound like a traditional educational institution, but it is far from it. Founded in 1976, it offers a broad range of traditional academic degrees ranging from bachelors of arts to doctorates. University of Phoenix now has almost 280,000 students attending its classes - more than half of these students attend "virtually", enrolling and taking classes through the Internet. The rest of the students attend classes on a distributed campus, encompassing facilities in 34 different states. University of Phoenix has been one of the leaders in recognizing that education is becoming much more of a life-time learning experience. To serve its students more effectively, it became one of the pioneers in using the Internet to help students pull educational resources to them when and where they wanted to participate in the learning process. While the timing and delivery of these educational materials is customized, the materials themselves are still highly standardized, in part because of the need to comply with certification requirements. In part because of the standardization of materials, the University of Phoenix can experiment actively in the design and delivery of its educational programs and maintain tight feedback loops, making it a learning institution, rather than simply an institution of learning.

When we move from the University of Phoenix to Cisco, we leave the world of formal educational institutions, but we don't leave the world of learning. In fact, innovative approaches to learning represent one of the key foundations for the success of the global process network in customer relationship management deployed by Cisco. Cisco has been a pioneer in the deployment of a robust e-learning platform that allows over 40,000 of its distributed channel partners with combined sales and technical staffs of over 400,000 employees to access training modules when then need arises.

Providing effective learning tools to such a large and distributed group of people can certainly be intimidating. Cisco has addressed this challenge by deploying learning portals on the Internet to serve the specific learning needs of its direct sales force, its system engineers and its channel partners. Robust search technology using metadata tags helps users of these portals to locate the learning modules that are most relevant to them in any particular context. This search capability is complemented by tailored learning roadmaps designed for various categories of users, helping to guide them to the useful learning modules at various points in their development. Cisco is working on personalizing this e-learning capability even further by understanding the specific work context of each employee and offering prescriptive recommendations regarding learning resources that might be particularly helpful. For example, if a sales person has scheduled a sales call with a financial services company, the e-learning system might proactively suggest that the sales person review a new learning module on new product features that are of particular interest to financial services companies. Cisco has so many specialized products and such frequent enhancements to existing products that this form of tailored information delivery becomes invaluable in helping specialists in the field to keep up with the latest offerings and capabilities.

This e-learning platform provides a variety of benefits including the enhanced ability to present a common face to the customer across very diverse distribution channels. Where uniformity is required, as in standardized levels of technology expertise, Cisco's e-learning platform helps to ensure this while at the same time effectively deploying more specialized skills where required. By helping to accelerate the learning and development of employees in its channel partners, Cisco also wins greater loyalty from its channel partners - they are far less likely to drop Cisco as a partner and they are more likely to provide preferential support for Cisco if they serve other vendors as well.

Cisco's e-learning platform also fosters a shared vocabulary, set of methodologies and perspectives regarding technology architectures and evolution. This helps to set the stage for deepening trust and enhancing the ability to collaborate effectively. As a result, it also helps to increase the potential for business innovation. Given 
shared frameworks for understanding, employees from Cisco and its diverse channel partners can quickly assemble to address unexpected challenges or opportunities in the marketplace and come up with innovative new business approaches.

So far, the examples we have cited are more in the category of training, involving the dissemination of highly codified information. What about deeper learning where new practices are being developed and where tacit knowledge becomes more central to the learning process? For inspiration regarding pull based models of learning, we should look even further outside the domain of traditional educational institutions to the world of open source software.

Most discussions of open source software focus on the innovative techniques used to produce complex software for specific computing and application environments by mobilizing highly distributed programming talent. In this context, open source software represents another very interesting pull model emerging in the production sphere. But far fewer observers note the significance of open source software as a highly effective platform for learning through apprenticeship. Open source programmers often start with code developed by others and then develop enhancements required for specific environments. As the code is developed, it is posted for use by a broad community of more experienced programmers. In fact, programmers learn to write code in ways that facilitate reading by others, a key sensibility acquired in open source efforts. Because the code can be executed right away, the developers receive rapid feedback. Participants in open source projects thus learn at four levels - they observe and work with the code of others, they observe their own code in action, they get feedback and commentary from others executing their code and they have access to feedback and commentary from others regarding code developed by other open source programmers. These participants begin as legitimate peripheral participants and, as they build their skills through creation of their own code, they advance to become coaches and mentors of others. In this manner, participants structure their own learning environments and they pull the resources required for learning when it is most relevant and useful for them.

\section{Forces Driving the Search for Alternative Mobilization Models}

Five broad forces are undermining the viability of the "push" mobilization model and shaping the quest for a new, more flexible approach to resource mobilization.

\section{Increasing Uncertainty}

As interaction costs decline and as barriers to entry erode, markets and social institutions evolve more rapidly, often in unanticipated directions. Product and service life cycles are compressing, further compounding uncertainty as vendors more frequently confront the challenge of introducing new products and services and the uncertainty as to whether these new generations of products and services will find a receptive market. Demand becomes more uncertain and the resources required to meet that demand change more rapidly.

Push models are most efficient in stable environments, when demand for specific resources can be anticipated reliably. The fundamental assumption of push models is that demand can be predicted reliably enough to define the procedures required to deliver resources to pre-specified locations before the demand actually materializes. Push models therefore require accurate forecasts to function effectively. Uncertainty undermines the ability to forecast and this in turn undermines the ability to push resources to the right place at the right time. Managers try to compensate for this growing uncertainty with a dizzying array of options, derivatives and other forms of hedges, but these are patches on a more fundamental problem: it is harder and harder to deploy resources in anticipation of demand.

\section{Growing Abundance}

"Push" models work best when there are a fixed - and relatively limited - number of inputs. As the range of resources expands, complexity mounts. Since push models rely on central planners to deploy resources in anticipation of demand, this complexity overhead quickly becomes unbearable. The breaking point comes even 
more quickly if the resources rapidly evolve.

The Internet and public policy shifts reducing barriers to entry on a global scale have led to an abundance of resources, making it difficult for conventional push models to work. Information is certainly the resource that has proliferated most broadly. One study ${ }^{\mathrm{ii}}$ at Berkeley estimates that the amount of new information produced in 2002 alone on print, film, magnetic and optical media reached about 5 exabytes, or 5 billion gigabytes. The Berkeley study estimates that new information produced on paper alone in 2002 was 1,634 terabytes, equivalent in size to the information contained in 163 new libraries the size of the Library of Congress print collections.

Yet, the growing abundance is certainly not limited to information. Products and services have proliferated, as the Internet has made it easier to connect producers of highly specialized products and services, wherever they reside in the world, with consumers looking for these specialized products. The number of products and services accessible at any given point in time is expanding, but product life cycles are also compressing, significantly increasing the rate of change in products and services available. Communities of people with similar interests and/or practices have also become more abundant, given the ability of the Internet to more effectively connect people with complementary capabilities regardless of location.

Under conditions of growing abundance, push models become untenable. For example, traditional advertising approaches built upon a push model begin to break down as audiences become overwhelmed with the number of messages. More clever targeting techniques may help in the near-term, but ultimately advertisers confront rapidly diminishing return on attention as spending to find and reach potential customers escalates and the impact in terms of increased likelihood of purchase diminishes. Similarly, under conditions of growing abundance, the value of editing increases but traditional approaches to editing become less and less viable as individual editors struggle to keep up with the growing array of resources.

\section{Intensifying Competition}

Intensifying competition drives a need to access specialized world-class capabilities. This has led to a rapid growth in outsourcing activity. So far, most of this outsourcing activity has concentrated on generic and secondary activities within the enterprise, especially IT operations management and administrative processes like HR and finance and accounting. In these areas, it is common for outsourcing customers to rely on a single outsourcing provider for the specific activity.

As more companies decide to outsource core operating processes like logistics, manufacturing and product innovation, we will encounter a growing need to access a broader range of specialized outsourcing service providers. The example of Li \& Fung cited earlier illustrates the growth in complexity - it orchestrates 7,500 business partners in 37 countries.

Push models require tight definition and standardization of procedures to be effective. For this reason, push models have a difficult time scaling beyond the boundaries of the enterprise, unless there is a company like Wal-Mart with such market power that it can impose its detailed and standardized procedures on a large number of reluctant participants. Otherwise, the complexity overheads created as the number and diversity of enterprises participating in an extended business process will rapidly overwhelm the capacity of conventional push models.

\section{Growing Power of Customers}

As customers gain access to a greater number of options and more information about those options, they become more demanding on resource providers, requiring resources to be made available on their terms, when and where they want them, rather than when and where it is convenient for the resource providers to deliver them. Even in such commodity product categories as cement, companies like Cemex in Mexico have prospered by developing more responsive delivery systems for their customers. In addition, customers are increasingly demanding the ability to configure their own products and services from modular components supplied by the vendor, leading to further proliferation of options. For example, the desire to obtain specific music tracks rather than an entire pre-packaged 
album of songs has spawned the rapid growth of online music networks serving that need. At the extreme, customers are demanding and receiving tools to create their own products and services, bypassing entire tiers of product and service vendors. Relatively inexpensive digital editing tools like iPhoto and iMovie are undermining the traditional role of specialized film processors. This growing power of customers is playing out at all stages of industry value chains, not simply at the ends of these value chains.

\section{Greater Emphasis on Learning and Improvisation}

Given the combination of forces above, people in all walks of life are finding a need to learn new skills and acquire knowledge on a continuing basis. Even more challenging, the nature of what must be learned and the timing of the learning need are becoming much harder to anticipate. As discussed earlier, Cisco is striving to address this reality with its e-learning platform. People must also find ways to improvise their work practices to respond to unanticipated needs. Traditional push models of education and process management have limited value when the specific focus of learning or work activity cannot be determined in advance. For example, push models of education work best when the content of what must be learned has been codified well in advance and when the timing and sequence of what must be learned can be anticipated or, at least, there is an authority that is credible enough to assure students that the material will eventually be useful. These pre-requisites for push models of education are harder and harder to find in rapidly changing and increasingly uncertain environments. Programmatic training models must increasingly be replaced, or at least supplemented, by more flexible coaching and apprenticeship models of education.

\section{Push versus Pull - Contrasting the Two Models}

Pull approaches to resource mobilization require fundamentally different ways of organizing resources and management techniques relative to push approaches. Push approaches are typified by "programs" - tightly scripted specifications of activities designed to be invoked by known parties in pre-determined contexts. Of course, we don't mean that all push approaches are software programs - we are using this as a broader metaphor to describe one way of organizing activities and resources. Think of thick process manuals in most enterprises or standardized curricula in most primary and secondary educational institutions, not to mention the programming of network television, and you will see that institutions heavily rely on programs of many types to deliver resources in pre-determined contexts.

Pull approaches, in contrast, tend to be implemented on "platforms" designed to flexibly accommodate diverse providers and consumers of resources. These platforms are much more open-ended and designed to evolve based on the learning and changing needs of the participants. Once again, we do not mean to use platforms in the literal sense of a tangible foundation, but in a broader, metaphorical sense to describe frameworks for orchestrating a set of resources that can be configured quickly and easily to serve a broad range of needs. Think of Expedia's travel service or the emergency ward of a hospital and you will see the contrast with the hard-wired push programs. Let's looks at push and pull models in a little more detail.

\begin{tabular}{|l|l|}
\hline Push Programs & Pull Platforms \\
\hline Demand can be anticipated & Demand is highly uncertain \\
\hline Top down design & Emergent design \\
\hline Centralized control & Decentralized initiative \\
\hline Procedural & Modular \\
\hline Tightly coupled & Loosely coupled \\
\hline Resource centric & People centric \\
\hline Participation restricted & Participation open \\
Few participants & Many diverse participants \\
\hline Efficiency focus & Innovation focus \\
\hline Limited number of major re-engineering efforts & Rapid incremental innovation \\
\hline Zero sum rewards & Positive sum rewards \\
Extrinsic rewards dominate & Intrinsic rewards dominate \\
\hline
\end{tabular}




\section{Push Programs}

Push programs represent a top down approach to dictating activities. These programs tend to specify activities or procedures in detail. The core assumption of push programs is that demand can be anticipated and that it is more efficient and reliable to mobilize resources in pre-specified ways to serve this demand. These activities or procedures may be organized into modules (for example, semesters in a curriculum), but that is only for the convenience of the provider. The modules are usually tightly coupled - deployed in a pre-specified sequence.

Because of the work required to specify, monitor and enforce detailed activities, push programs tend to be restricted in terms of the number and diversity of participants. This is especially true beyond the boundaries of a single institution where the complexity overhead increases exponentially as the number and diversity of participants grows. This is a key reason why most large companies have worked so hard to reduce the number of suppliers in their supply chains. Even within a single institution, push programs specify the type of participants, their roles and the sequence of their involvement in the activities covered by the program.

As a result of the tight coupling of the procedures in these programs, their designers tend to limit the frequency of enhancements to these programs. Modifications in one part of these programs can often cause significant and unanticipated disruptions in very different parts of the programs. For this reason, designers tend to approach modifications very cautiously and bunch them together into major re-engineering efforts, as we see in the arena of business process management.

Push programs tend to treat all relevant resources as a fixed and scarce quantity - after all, that is one of the rationales for a push program to begin with: to ensure that scarce resources are deployed to the highest priority needs. If one participant gets the resources or the rewards, other participants must do without. In this sense, push programs operate with zero sum reward systems for their participants. Often there is intense political maneuvering to gain privileged access to resources. Since the availability and movement of resources are dictated from above, political maneuvering focuses on influencing the center. The key planning instruments of push programs are budgets (for financial resources) and materials requirement plans (MRPs - for physical resources) - these become the focus of intense political rivalry.

Reward systems tend to concentrate on extrinsic rewards - for example, money or grades. Participants in push programs are generally treated as instruments to ensure that activities are performed as dictated - their own individual needs and interests are purely secondary, if relevant at all. As a result, these programs generally tend to default to extrinsic rewards as a way to motivate participants.

Push programs adopt a standard meta-design pattern where construction and creation are clearly separated from use or consumption:

- $\quad$ Design - define specific procedures and specify people that must execute the procedures

- Deploy - build dedicated facilities, train the people, secure the resources

- $\quad$ Execute

- $\quad$ Monitor

- $\quad$ Refine - address specific performance gaps or introduce enhancements on schedules determined by the program designer

\section{Pull Platforms}

The contrast of push programs with pull platforms is quite stark. Pull platforms tend to be much more modular in design but now the modules are for the convenience of the participants of the platform. Modules are created to help to make resources and activities more accessible in flexible ways since the core assumption of pull platforms is that the needs of participants cannot be well anticipated in advance. Pull platforms are designed from the outset to handle exceptions, while push programs treat exceptions as indications of failure. 
In pull platforms, the modules are designed to be loosely coupled, with interfaces that help users to understand what the module contains and how it can be accessed. In the case of global process networks like the one orchestrated by Li \& Fung, each business partner represents a module. Li \& Fung excels in understanding how to rapidly configure modules to create complex and highly customized supply chain operations on a global scale. Because of this loosely coupled modular design, pull platforms can accommodate a much larger number of diverse participants. In fact, pull platforms tend to have increasing returns dynamics - the more participants and modules the platform can attract, the more valuable the platform becomes. As Li \& Fung adds more specialized participants, it can deliver even more value to its customers by matching the specialized capability of its partners to the individual needs of customers. The business partners also benefit because they are able to specialize in areas of truly distinctive capability and to focus on accelerating their capability building to create even more value. In many cases, pull platforms are initially deployed to serve a specific need but, because of the flexible design, these platforms rapidly evolve in unexpected directions and end up serving a much broader range of needs. Instant messaging networks were initially deployed to help teens and hackers to communicate more rapidly but are now actively used by financial traders to gain an edge in rapidly moving financial markets. The design of these platforms is emergent, shaped by the participants themselves as their own needs evolve. Because of this capability for rapid evolution, pull platforms are key to accelerating capability building.

Pull platforms are enhanced much more frequently than push programs. These enhancements can occur at multiple levels. Modules may be recombined in innovative ways to serve new needs. Li \& Fung can rapidly reconfigure its global operations in response to unanticipated political instability in certain countries. Activities and resources within modules may be reconfigured through improvisation and experimentation to serve needs more effectively. Since Li \& Fung does not dictate how its partners operate within their plants, the managers of these partners are free to experiment with new approaches to running their operations. Because these modules are relatively self-contained, this improvisation and experimentation does not introduce as much risk of widespread unanticipated adverse effects as in tightly specified push programs. Finally, enhancement can occur through the addition of new layers to the platform as participants discover entirely new ways to add value by leveraging the capabilities of deeper layers. We will explore the diverse layers of pull platforms in more detail below.

Pull platforms make it easier to assemble participants and resources on an ad hoc basis to problem solve unforeseen issues or situations. As a result, they enhance the potential for productive friction as people with different perspectives, skills and experiences come together to try to find a solution for a specific problem. In contrast, push programs view all friction as an inefficiency that must be eliminated. The purpose of tightly specified programs is to eliminate wasteful debate and disagreement, especially at the point of execution.

Since pull platforms are designed to easily accommodate new participants and to create new value in innovative ways, they tend to generate positive sum reward systems for participants. The innovation of each participant enhances the overall value of the platform, creating a larger pool of rewards that can be distributed among the participants. As pull platforms attract additional participants, they also encourage more specialization of capability so diverse niches emerge and evolve, reducing head to head competition and commoditization. Positive sum reward systems reduce the perceived need for political maneuvering and the opportunity to connect on a peer to peer basis with resource owners diminishes the role of the "center" as a focus for resource allocation.

Because pull platforms can be flexibly configured to serve the individual needs and interests of each participant, they provide much greater opportunity for intrinsic rewards as a key motivator for participation. Look at the rapid growth of wikipedia, the online encyclopedia emerging from the contributions of thousands of volunteer participants. Because these contributors participate based on interest, they are motivated by the desire to contribute and share their interests with others. Of course, extrinsic rewards will still play a prominent role in many pull platforms, but they will be balanced by a much more significant opportunity to pursue intrinsic rewards as well.

Pull platforms tend to focus on the following activities, resulting in a blurring of the boundaries between creation and use: 
- $\quad$ Find - not just raw materials, products and services, but also people with relevant skills and experience. Some of the tools and services that pull platforms use to help participants find relevant resources include search, recommendation engines, directories, agents, social network software and reputation services. Web services technology provides a useful set of standards to help participants find resources and understand the services that the resources can provide. For example, Web Services Description Language (WSDL) establishes a standardized way of describing the resources available in a Web service.

- Connect - again, not just raw materials, products and services, but also people with relevant skills and experiences. Performance fabrics discussed below will be particularly helpful in establishing appropriate connections. Within these performance fabrics, new technology architectures will help to define broadly used protocols to establish effective connections with relevant resources. The mobile Internet is dramatically extending our ability to connect wherever we are. Social networks will help to build the shared meaning and trust required to make resources available in the first place.

- Innovate - pull platforms provide much more flexible environments for participants to innovate with the resources made available to them. This innovation could take many forms including creative ways of orchestrating resources, for example recombining and remixing, to deliver more value. The innovation may involve creation of entirely new resources or more modest improvisation and tinkering with existing resources to enhance their functionality and performance. Participants in pull platforms rarely just "use" the resources made available to them - they become actively involved in modifying the resources to more effectively serve their needs. Collaboration spaces provided by social software can provide rich environments for innovation with others.

- $\quad$ Reflect - reflection of course is also feasible in push models, but it tends to occur in a much more centralized and episodic fashion. Pull models are designed to enable the distributed participants to reflect on the performance of resources available to them and then to recombine or improvise with much more rapid feedback regarding the impact of these efforts. The distributed participants have a much richer and nuanced understanding of the local context of their performance and are therefore better positioned to develop appropriate approaches to improve performance. In addition to local reflection, analytic tools designed to help participants identify patterns in performance can help to enhance reflection on the performance of broader elements of the pull platform and support broader-based innovation initiatives.

\section{Exploring the Layers of Pull Platforms}

Pull platforms are best understood as loosely coupled layers that are evolving at a different pace in various industries or institutional environments. These layers progress from a high tech focus in the lower layers, shaping communication and logistics networks, to a high touch focus in the upper layers, concentrating on mobilizing individuals and communities to innovate and create new value. These layers can be included or excluded in specific pull platforms, depending on the needs of specific resource mobilization situations. The four activities characteristic of pull platforms as described above - find, connect, innovate and reflect - can be found within each layer of pull platforms. In fact, they are the driving force in the rapid evolution of each layer. These layers co-evolve in interesting and complex ways. For example, the changing needs of "higher" layers like global process networks will provide a catalyst for innovation in "lower" layers and the changing capabilities of "lower" layers will create new options for enhancing the configuration and functioning of "higher" layers.

Proceeding from the bottom layers upward, these layers fall into three broad categories - infrastructure, performance fabrics and creativity frameworks. 


\begin{tabular}{|l|l|}
\hline Infrastructure layers & Establish connections \\
\hline 1. Communication and logistics networks & Facilitate basic movement of information and goods \\
\hline 2. Service grids & $\begin{array}{l}\text { Provide enabling services to create more robust and } \\
\text { tailored connections }\end{array}$ \\
\hline Performance fabric layers & $\begin{array}{l}\text { Make existing resources more available } \\
\text { Create more flexible ways of organizing and mobilizing } \\
\text { resources }\end{array}$ \\
\hline 3. Technology enablers & $\begin{array}{l}\text { Increase willingness and ability of people to share } \\
\text { resources, especially knowledge }\end{array}$ \\
\hline 4. Social networks & Create new resources \\
\hline Creativity framework layers & $\begin{array}{l}\text { Create metadata to help connect participants and } \\
\text { resources }\end{array}$ \\
\hline 5. Aggregation networks & $\begin{array}{l}\text { Orchestrate capabilities to create new products and } \\
\text { services }\end{array}$ \\
\hline 6. Process networks & $\begin{array}{l}\text { Establish collaborative environments for participants to } \\
\text { generate new practices }\end{array}$ \\
\hline 7. Networks of creation & \\
\hline
\end{tabular}

\section{Infrastructure Layers - Establish Connections}

These layers provide the foundations for a pull platform stack. Pull platforms require ubiquitous, flexible and highly reliable connections to function effectively. These foundation layers focus on establishing the connections themselves rather than on the resources or participants that are being connected. Since pull platforms are generally open to a broad range of participants, these layers are characterized by a strong "out-in" focus addressing the challenge of connecting highly dispersed resources across a diverse set of institutional environments.

Layer 1 - Communication and logistics networks. At the most basic level, pull platforms require some way for participants to communicate their needs to resource owners and, where physical resources are involved, to move the required resources quickly and cost-effectively to the participant. In terms of communication capability, the Internet as a shared infrastructure has become an important foundation layer for many pull platforms. It is particularly valuable in facilitating peer to peer networks that can remove the chokepoints in terms of scaling encountered in more conventional centralized networks. The ubiquity and high speed capability of this infrastructure has been further enhanced by the deployment of wireless networks, broadband local access networks and a growing diversity of intelligent mobile access devices. Nevertheless, pull platforms do not require the Internet, as the example of Li \& Fung's global process network illustrates, although even Li \& Fung would be challenged without basic telephone and fax communication networks. Logistics networks like UPS and container shipping networks also provide critical foundations for pull platforms involving physical goods.

Layer 2 - Service grids. Service grids help participants in pull platforms to create more robust, mediated and tailored connections by accessing and configuring enabling services, Service grids provide four broad categories of managed services:

1. Shared utilities provide services that support not only the users of service grids but also the other utilities within the service grid. There are three types of shared utilities. Security utilities provide services like authentication, authorization, and accounting. Performance auditing and assessment utilities provide assurance to users that they will obtain agreed-upon levels of performance and will be compensated for damages if performance falls below these levels. Billing and payment utilities aggregate charges for the use of services and ensure prompt and full payment.

2. Transport management utilities include messaging services to facilitate reliable and flexible communication across resources and participants as well as orchestration utilities that help companies assemble sets of resources from different providers.

3. Resource knowledge management utilities include directories, brokers, and common registries that describe available resources and determine correct ways of interacting with them. They also include specialized services for converting data from one format to another. 
4. Service management utilities ensure reliable provisioning of services, including release management as new enhancements are introduced. They also manage sessions and monitor performance to ascertain conformance to service quality specifications and service-level agreements.

Think of service grids as flexible frameworks for orchestrating loosely coupled modules of enabling services provided by a variety of specialized third parties. Enabling services focus on enhancing the functionality and performance of connections - they don't directly provide application functionality, but instead help to establish robust connections tailored to the requirements of specific application environments. This functionality is analogous to middleware for enterprise applications, only in this case it is delivered as a set of managed services rather than as installed software. For example, a service grid to support large financial transactions would provide much higher levels of security than a service grid to support sharing of photographs like the virtual private networks provided by Grouper. Service grids represent a natural complement to the capabilities now becoming available through various implementations of "cloud computing." Cloud computing seeks to make core technology resources - processing, storage and bandwidth - available as services that can be accessed over the Internet from centralized facilities. Service grids organize and deliver the specialized enabling services described above to ensure that connections across distributed locations perform seamlessly, reliably and securely. Just as technology resources are now becoming available as services, the middleware that used to be installed on our computers will also become available as a service.

\section{Performance Fabric Layers -Make Existing Resources More Available}

Performance fabrics weave together two layers - technology enablers and social networks - to help participants access resources across the connections established by the bottom two layers of pull platforms. At these layers, the attention shifts to the participants and the resources at the end of the connections and focuses on what is required to make these resources and participants more accessible.

Layer 3 - Technology enablers. These include both tools and architectures designed to help participants mobilize and work with resources more flexibly. Social software represents one set of technology tools that is particularly helpful in the construction of pull platforms. For example, wikis help participants in pull platforms to quickly establish collaborative work spaces where they can post documents and other resources for groups to work on. Other technology tools help participants to recombine, improvise on, tinker with and reflect on the resources that are mobilized. For example, less expensive digital photography applications allow amateur photographers to manipulate digital images in ways that were only available to professional photographers a decade ago. Two technology architectures that are particularly helpful for the construction of pull platforms are service oriented architectures (SOAs) and virtualization architectures. SOAs help participants to mobilize applications and data required to support their work. Virtualization architectures help to rapidly configure the appropriate hardware building blocks computing, storage and network resources - required to support broader work on pull platforms. SOAs and virtualization architectures amplify the power of social software by making it easier for participants to mobilize resources more flexibly to support their collaborative activity.

Layer 4 - Social networks. At this level, participants in pull platforms connect with each other and build relationships through the development of shared meaning and trust. These relationships amplify the power of technology enabled connections by enhancing the willingness and ability of participants to share resources, especially knowledge, with each other. Reputation mechanisms like credit reporting firms and product evaluation services help to build trust and amplify reputation building. Certification agencies like professional associations help to create standards for evaluating the capabilities of participants in pull platforms.

\section{Creativity Framework Layers - Create New Resources}

In these layers, participants collaborate to build new resources and to more effectively orchestrate creative efforts to support the needs of specific customers. Pull platforms ultimately exist to support the creative activity of their participants. It is in these upper layers that the creativity of participants is focused and organized to deliver value to the users of pull platforms. 
Layer 5 - Aggregation networks. These networks focus on bringing together a broad spectrum of specialized resources for customers and providing customers with tools and information to find the resources that are most relevant to their needs. They leave it up to the customers to select the appropriate resources and, where necessary, to organize these resources to perform specific services. Examples of aggregation networks include Amazon, eBay and Netflix. The organizers of these resources represent a new kind of intermediary, often hosting more specialized organizers of resources in their networks, as in the example of Amazon helping to connect customers with more specialized retailers. In the Amazon case, the more specialized retailers play the role of editors, but the aggregation network organizer is not an editor, at least in the conventional sense - the organizer strives to include all available resources so that customers themselves can choose.

While these networks do not directly create new resources, they generate rich new information or meta-data about existing resources, as illustrated by the reviewers on Amazon or the reputation ratings of vendors on eBay. In some cases, like Schwab, they aggregate considerable third party information about resources and then provide participants with analytic tools to create their own meta-data about the resources. By creating analytic tools and meta-data to help participants connect more effectively with specialized resources, these aggregation networks increase the economic incentives for the production of new specialized resources.

Layer 6 - Process networks. Process networks provide a flexible way to access and orchestrate the capabilities of specialized participants to generate even more tailored value for customers. Unlike aggregation networks, the orchestrators of process networks develop deep capabilities in terms of understanding the needs of their customers and selecting the right participants in the right sequence to deliver more value for their customers. Orchestrators of process networks recruit appropriate participants into the network, build relationships with customers to better understand their needs and then mobilize the appropriate participants to serve these customer needs. In the business arena, process networks help to organize resources and activity in three major core operating processes - supply chain management, product innovation and commercialization and customer relationship management. Process networks may be orchestrated by specialized third parties like Li \& Fung or by companies that want to amplify the value of their core business like Nike or Cisco. These process networks will become especially important in creating pull distribution platforms to help connect providers of highly specialized resources with customers that would value these resources. As a result, these process networks will also create significant economic incentives for the proliferation of even more specialized capability.

Layer 7 - Networks of creation. So far, we have been talking about the networks that help to connect specialized participants with each other. This layer focuses on the nodes of these networks and the environments within which these nodes are embedded. At this layer, participants of pull platforms come together to focus and amplify their creative efforts. These networks of creation mobilize capability in a variety of arenas, including communities of practice, networks of practice and specialized local ecosystems bringing together complementary capabilities. These networks of creation serve a variety of functions - they provide environments that help participants to connect with each other in order to innovate, learn, build new capabilities and create new resources. Within these environments, the inevitable friction of collaborative innovation becomes highly productive and participants are able to accelerate their capability building. Ultimately, pull platforms exist to serve the needs of these networks of creation - they amplify the creative capability of these networks by providing them with more flexible and ubiquitous access to the resources that they may require. Since needs can never be fully anticipated in creative activities, push programs inevitably constrain the creative process while pull platforms expand the degrees of freedom available to participants.

\section{Understanding the Spectrum from Push to Pull}

Pull platforms and push programs are not mutually exclusive. In fact, pull platforms often contain push programs as resources accessible through their platforms. For example, Li \& Fung operates a highly flexible pull platform through its global process network, yet many of the apparel producers that participate in its network organize their own resources through push programs. Pull platforms often emerge as overlays that help to connect operators of push programs more effectively with potential customers. For example, think of Amazon or eBay providing robust pull capability for consumers to access on demand products like books that were produced using 
traditional push manufacturing programs, but then reflect on the opportunities created by these pull distribution systems to reconfigure the underlying production processes by creating pull platforms like publishing on demand. Designers of resource mobilization systems need to think through carefully at what levels in the system or under what circumstances push models may be more appropriate than pull models and how these two models might intersect. For example, Benetton is well known for its production of white apparel designs that can then by dyed at the last moment before shipping and perfecting techniques for dyeing fabric in ways that reliably replicate the colors achieved when dyeing fibers before they are woven into fabric.

More broadly, however, the forces outlined earlier are making it more and more attractive to deploy pull models rather than push models. At the same time, broader deployment of more flexible technologies, tools and infrastructures is making it more viable to design and manage pull models. As a result, we expect that pull models will increasingly displace or marginalize push models in broader arenas of human activity.

In thinking about the movement from push to pull models of resource mobilization, it is important to understand that Toyota and other practitioners of lean manufacturing techniques represent a transitional stage on this trajectory. Toyota operates its assembly lines with a "just in time" philosophy. Resources are pulled into the assembly line just as they are needed, rather than allowing large inventories to accumulate at various stages of production. In its Japanese operations, Toyota is not quite at the point of attaching a customer's name to each car entering the production process, but it is much closer to executing a true "build to order" system than U.S. car manufacturers. In all these respects, Toyota and other lean manufacturing practitioners have begun a move to pull models of resource mobilization. Think of what this does for the motivation of the workers on the assembly line. In the plants of U.S. manufacturers, they come to work passing huge lots of cars waiting for someone to want them. As the workers start producing even more cars for the lot, it is hard to build any sense of urgency or connection to the ultimate customer, thereby increasing the need for extrinsic rewards like cash compensation to motivate the workers.

Yet, in other respects, these practitioners continue to employ significant elements of push programs. For example, to make this particular form of pull work, Toyota significantly limits the number of suppliers that it deals with and tightly integrates its operations with these suppliers, often requiring co-location of facilities to reduce cycle times and enhance potential for rapid problem-solving. Activities throughout its operations are highly specified and standardized. In other words, Toyota has been able to achieve high flexibility in its operations by closing its system and significantly limiting the diversity of participants. Perhaps by developing performance fabric layers of a pull platform, Toyota might find a way to extend its lean manufacturing system to include a much broader range of highly specialized suppliers. As this example illustrates, push and pull models are rarely encountered in pure form most resource mobilization systems employ elements of both models.

It is best to think of push and pull models along a continuum rather than as a set of binary choices. For example, the ability to target advertising to individuals based on context to ensure relevance and timeliness is a significant advance relative to more conventional push models of mass market advertising where everyone received the same advertising message at the same time, largely independent of context. Yet, this form of advertising is still not a "pull" model where individuals select what advertising, if any, to view. Once again, however, we believe that the forces and capabilities discussed earlier will make it more and more attractive and rewarding for organizers of these systems to employ more elements of pull models.

\section{The Value of Pull Platforms - Innovation, Learning and Capability Building}

Pull platforms offer significant benefits relative to push programs. They foster more innovation, enhance opportunities for collaboration and enable much more leverage in terms of mobilization of third party resources. Institutions that learn how to harness the capabilities of pull platforms will be able to create substantially more value relative to companies that continue to pursue push programs.

As should be clear by now, pull platforms significantly enhance the potential for distributed innovation by helping participants to more flexibly mobilize resources. The participants using the available resources are able to orchestrate, create, improvise and tinker with these resources in ways that are simply not feasible in conventional 
push programs. Participants also receive much more rapid feedback regarding the results of their own local innovation as well as the local innovation of others.

Too often, when observers talk about pull models, they tend to discuss these models in the context of individuals seeking and using resources. This is one important dimension of pull models, but this frame of analysis obscures an even more important dimension of pull models. Pull platforms enable the formation and functioning of distributed communities that can rapidly improvise and innovate given the enhanced flexibility of resource mobilization. These communities can also amplify the power of reflection and accretion by bringing together a diverse and often distributed set of participants. Self reflection is much more difficult and limited in terms of insight relative to the kind of reflection that can occur in communities of practice where deeply engaged practitioners challenge each other to reach new levels of awareness and understanding.

Pull platforms become powerful vehicles for leverage, allowing participants to more effectively mobilize diverse and distributed resources from a broad range of providers. As discussed earlier, push models are much more difficult to scale beyond an individual institution and therefore tend to limit the potential for leverage unless the institution has so much power that it can mandate standardization of procedures across other less powerful institutions.

Pull platforms thus harness collaboration and leverage to amplify creativity and innovation. But they do more than this. They also help to accelerate learning and capability building. Pull platforms represent continuous learning environments where participants come together and learn from each other as they tackle a series of unanticipated "action points" - situations requiring very specific choices or decisions. By providing highly flexible environments where participants can access the contributions of others, pull platforms facilitate learning from others as well and encourage participants to focus on areas where they can be truly distinctive. As a result, participants are able to build capabilities much more quickly by working with others to bootstrap their own capabilities.

\section{Implications of Pull Platforms for Business Executives}

To harness the potential of pull platforms for innovation, collaboration and leverage, business executives will need to systematically reassess all aspects of the enterprise.

Mindset. Key assumptions about what is required for business success will need to be challenged and redefined. For example, push programs are built upon the assumption that the best way to deal with uncertainty is to increase control over relevant resources. Pull platforms require executives to forego control and to rely on individual initiative to identify and mobilize relevant resources at the appropriate time. Rather than viewing uncertainty as a threat that needs to be minimized, pull platforms are built upon the assumption that uncertainty represents an opportunity for more innovation and value creation.

Business definition. Companies will face difficult choices regarding business focus. Push programs typically require companies to bundle together three fundamentally different businesses: infrastructure management businesses, customer relationship businesses and product innovation and commercialization businesses. These businesses require different economics, skill sets and cultures to be successful, yet most companies continue to seek to manage all three businesses within their enterprise boundaries in an effort to establish tighter control over all the resources and activities required to deliver value to customers. As more versatile pull platforms become available, companies will no longer need to participate in all three businesses. They will be able to focus on becoming worldclass within one business and rely on other companies to supply the elements of the other two types of business. In fact, greater focus will become a necessity as pull platforms make it easier for focused companies to compete based on world class capabilities.

Strategy. As pull platforms emerge and evolve, business strategy will need to be redefined. Strategic advantage will depend less on the resources a company owns and more on the insight and capability in finding and mobilizing the resources of others to add more value for customers. This insight and capability will need to rapidly evolve or else companies will be vulnerable to competitors using pull platforms to find and mobilize the same resources. 
Companies will need to explicitly decide what layers of pull platforms to develop themselves and what layers to rely on others to provide. Companies will need to resist the temptation to restrict access by others to any layers of pull platforms they choose to develop themselves. In an increasing returns environment, restricting access can rapidly lead to competitive disadvantage. Instead, companies should focus on strategies to define and disseminate de facto standards for organizing these layers. In the early stages of the transition from push programs to pull platforms, significant advantage will accrue to those who embrace pull platforms as they compete with companies committed to push programs. Over time, advantage will come from greater focus and accelerated capability building.

Operations. The core operating processes of the enterprise will need to be reconceived in light of the capabilities of pull platforms. For example, rather than focusing on customer relationship management, companies will need to master the techniques of participating in customer managed relationships. Instead of seeking to "own" the customer and build "walled gardens" around one-to-one relationships with customers, companies will become more adept at collaboration marketing, learning how to attract customers by becoming more helpful to them and by affiliating with other specialized third parties who can add even more value to the customer relationship. Rather than supply chain management, companies will need to master the techniques of demand network orchestration, mobilizing a broad range of specialized resource providers to deliver more tailored value to their customers. Similarly, product or service innovation will require much greater skill in knitting together internal resources with components supplied by complementary resource providers.

Organization. Leadership in pull-driven institutions requires a different style and set of skills relative to pushdriven institutions. Rather than relying on command and control, leaders of pull-driven institutions need to develop a deep understanding of what motivates participants, not only within their own institution but in other institutions owning resources that would add value to their customers. These leaders need to become adept at creating incentive systems that will help to align participants and create the conditions for productive friction to enhance the potential for innovation and learning. Rather than relying on extrinsic rewards, these leaders must learn to tap into appropriate intrinsic rewards.

Rationale for the enterprise. The modern industrial enterprise arose as a vehicle for efficiently designing and deploying push programs. In a world of pull platforms, the rationale for the enterprise itself must be re-examined. Enterprises will continue to add value in one of three ways: accelerating capability building within communities of practice, orchestrating capabilities across multiple enterprises in process networks or aggregating resources so that they can be more conveniently found and accessed by other participants in pull platforms. Ultimately, the success of these enterprises will depend on their ability to master different approaches to talent development, including the deployment of more flexible IT systems to support talent development. Training programs delivered to employees in a pre-determined sequence will diminish in importance relative to the creation of robust pull environments where participants (both employees of the enterprise and employees of business partners) can come together and learn more quickly as they seek to address the rapidly changing needs of their customers.

\section{Broader Implications of the Transition from Push to Pull Models}

These changes in the way we organize and manage firms represent only one dimension of the changes brought about by the transition from push to pull models. Pull models of resource mobilization are essential to unleashing the economics of the long tail as described by Chris Anderson. ${ }^{\text {iii }}$ Anderson tends to discuss the long tail in terms of connecting producers of highly specialized content with consumers seeking that content. This is only part of the story - pull models make specialization in the production of all kinds of products and services more viable and ultimately create significant economic incentives for even more specialization.

Pull models will also transform the social dimension of human activity. By making it easier for consumers to access resources required to fashion their own products and services, often in concert with others, pull models will accelerate a broader shift in our identity from consumers to networked creators. This shift will be reinforced by our increased participation in networks of creation that will employ pull models to help participants explore their passions and create new goods and services.

Pull models will also reshape learning dynamics. Rather than accessing and absorbing codified information on a pre-determined schedule, we will find ourselves accessing and joining relevant communities, often distributed 
across geographies, and participating in creation within these communities through apprenticeship models. We will spend less time at the outset "learning-about" and at an earlier stage we will begin the process of "learning-to-be" through participating in communities of practice. Pull models will make it easier for us to pursue diverse learning trajectories throughout our lives, shaping these trajectories in response to unanticipated needs and opportunities as they arise. We will also find it easier to pursue learning initiatives in concert with others who share our learning needs, wherever they are located. Social capital and intellectual capital will become increasingly intertwined as we find ways to collaborate with others to build knowledge through shared initiatives, pulling the resources required to support our initiatives as they evolve.

Pull platforms will set the foundations for individuals to pursue life-long learning agendas. Individuals will learn while creating and by creating. These individual learning programs will weave together with others in complex patterns, shaped by participation in diverse networks of creation and the interaction of these networks of creation in even broader networks. By facilitating these life-long learning agendas, pull platforms will contribute to self-actualization and reinforce the broader shift in identity from "consumer" to "networked creator."

Our political institutions will also be reshaped by the shift from push to pull. Rather than implementing push driven policies where needs are determined in advance, usually from the top down, and investments are made to address those needs, we will see more pull-oriented approaches to public policy. These pull oriented approaches will remove barriers to the movement of people and resources and create appropriate incentives for talent to seek out what it needs to develop more fully. The goal of these policies will be to accelerate talent development and enhance the potential for creation of new value through the evolution of more effective pull platforms. For example, public policies often focus on push programs for development of talent - agencies identify promising talent arenas and then design targeted subsidies to create training programs to develop specific skills. Pull-oriented approaches fostering freer movement of investment funds and more stable legal infrastructures are likely to be much more effective in enabling talent to find its highest value outlets and in creating more effective mechanisms for sustained and rapid development of that talent.

The developments in these various domains are not occurring in isolation. Early developments in each of these domains are folding back on and reinforcing movement in other domains. As a result, these early movements are picking up momentum and are likely to accelerate the broader transitions we have described above. In fact, we believe that these transitions are part of a move to fundamentally different common sense model that will shape how we view ourselves and the world around us, how we organize ourselves and relevant resources and how strive to improve ourselves. This new common sense model is a natural result of the development and deployment of microprocessor technologies and early Internet platforms that began to emerge in the early 1970's.

We are still in the relatively early stages of this transition to a new common sense model. The early signs are around us. Those who are alert enough to spot these signs and master the techniques required to effectively deploy pull models will be well positioned to exploit the opportunities created by this shift.

\section{Bottom Line for Executives}

\section{Competitive Strategy}

- $\quad$ Conduct a pull platform strategy diagnostic for your company. Establish a team consisting of five of your most promising young executives (no one over the age of 30) and five of your most creative and aggressive senior executives and give them the assignment to address the following questions:

$\circ \quad$ How vulnerable are your most profitable revenue streams to more focused competitors leveraging pull platforms?

- How effectively is your company harnessing the capabilities of existing pull platforms to deliver more value to customers?

- What would be the most significant opportunity to create a new pull platform to address the unmet needs of your current customers? 


\title{
Operations
}

- $\quad$ Select a key operating metric that determines the financial performance of your firm - for example, it may be customer churn rate, product development lead-times or defect rates in a manufacturing process. Create a team of line operating executives from the relevant functional areas and give them a stretch performance target in terms of improvement in the relevant operating metric. Ask them to identify how they might meet this performance target by deploying more pull capabilities within the operating process.

\section{Organizational Design}

- Identify a category of pivotal employees in your organization that have a disproportionate impact on the economics of your business. For example, in a high tech company, it may be the engineering team charged with designing the next generation product for the company. In a retailer, it may be the merchandising managers for the most profitable product lines. In a consumer goods company, it may be the brand managers. Establish a team of these pivotal employees and give them the assignment of designing a pull platform that would help them to improve their performance. Make sure that they have the freedom to specify what elements of the pull platform would reside within the enterprise and what elements would be provided by appropriate third parties.

- $\quad$ Establish a team consisting of high performing line executives from functional areas that interact frequently with other companies (e.g., procurement, sales or customer support) and high performing IT executives. Give them the assignment of designing a high level IT architecture from the outside-in - in other words, starting with the need to more effectively support coordination of activities across business partners and working back to what would be required to support internal activities.

\section{Endnotes}

\author{
${ }^{\mathrm{i}}$ NPR Talk of the Nation \\ 30 November 1999 \\ Timecode: $11 \mathrm{~min} 55 \mathrm{sec}$ \\ Link: discover.npr.org/features/feature.jhtml?wfId $=1067220$ \\ Also: www.npr.org/rundowns/rundown.php?prgld=5\&prgDate=30-Nov-1999 \\ ii "UC Berkeley study: amount of new information doubled in last three years." October 28, 2003. \\ http://www.universityofcalifornia.edu/news/article/5867 \\ iii “The Long Tail," by Chris Anderson, Wired, \\ http://www.wired.com/wired/archive/12.10/tail_pr.html
}

\section{REFERENCES}

1. $\quad$ Anderson, Chris (2006), The Long Tail. (New York: Hyperion)

2. Hagel, John III and Brown, John Seely (2005), The Only Sustainable Edge. (Boston: Harvard Business School Press)

3. Hagel, John III and Brown, John Seely (2006), Creation Nets: Harnessing the power of open innovation, unpublished working paper.

4. Hagel, John III and Brown, John Seely (2002), Service Grids: The Missing Layer in Web Services, Release 1.0, Volume 20, Number 11, 1-32 